\title{
Fluid flow and heat transfer of carbon nanotubes along a flat plate with Navier slip boundary
}

\author{
W. A. Khan $\cdot$ Z. H. Khan $\cdot$ M. Rahi
}

Received: 8 May 2013/Accepted: 26 May 2013/Published online: 12 June 2013

(C) The Author(s) 2013. This article is published with open access at Springerlink.com

\begin{abstract}
Homogeneous flow model is used to study the flow and heat transfer of carbon nanotubes (CNTs) along a flat plate subjected to Navier slip and uniform heat flux boundary conditions. This is the first paper on the flow and heat transfer of CNTs along a flat plate. Two types of CNTs, namely, single- and multi-wall CNTs are used with water, kerosene or engine oil as base fluids. The empirical correlations are used for the thermophysical properties of CNTs in terms of the solid volume fraction of CNTs. For the effective thermal conductivity of CNTs, Xue (Phys B Condens Matter 368:302-307, 2005) model has been used and the results are compared with the existing theoretical models. The governing partial differential equations and boundary conditions are converted into a set of nonlinear ordinary differential equations using suitable similarity transformations. These equations are solved numerically using a very efficient finite difference method with shooting scheme. The effects of the governing parameters on the dimensionless velocity, temperature, skin friction, and Nusselt numbers are investigated and presented in graphical and tabular forms. The numerical results of skin friction and Nusselt numbers are compared with the available data for special cases and are found in good agreement.
\end{abstract}

W. A. Khan · M. Rahi

Department of Engineering Sciences,

PN Engineering College,

National University of Sciences and Technology,

Karachi 75350, Pakistan

Z. H. Khan $(\bowtie)$

School of Mathematical Sciences, Peking University,

Beijing 100871, People's Republic of China

e-mail: zafarhayyatkhan@gmail.com
Keywords Carbon nanotubes - Flat plate . Navier slip boundary - Shooting method .

Nanofluids · Effective thermal

conductivity

\section{List of symbols}

$c_{p} \quad$ Specific heat, $\mathrm{J} / \mathrm{kg} \mathrm{K}$

$C_{\mathrm{f}} \quad$ Friction coefficient

$f \quad$ Dimensionless stream function

$k$ Thermal conductivity, W/m K

$\mathrm{Nu}$ Local Nusselt number

Pr Prandtl number of base fluid

$q_{\mathrm{w}} \quad$ wall heat flux, $\mathrm{W} / \mathrm{m}^{2}$

$\mathrm{Re}_{x} \quad$ Local Reynolds number

$T$ Local fluid temperature, $\mathrm{K}$

$T_{\infty} \quad$ Free stream temperature, $\mathrm{K}$

$u \quad x$-Component of velocity, $\mathrm{m} / \mathrm{s}$

$U \quad$ Free stream velocity, $\mathrm{m} / \mathrm{s}$

$v \quad y$-Component of velocity, $\mathrm{m} / \mathrm{s}$

$x \quad$ Distance along the plate, $\mathrm{m}$

$y \quad$ Distance normal to

the plate, $\mathrm{m}$

\section{Greek symbols}

$\alpha \quad$ Thermal diffusivity, $\mathrm{m}^{2} / \mathrm{s}$

$\beta \quad$ Slip parameter

$\phi \quad$ Volume fraction of ferrofluid

$\eta \quad$ Similarity variable

$\mu \quad$ Absolute viscosity, $\mathrm{N} \mathrm{s} / \mathrm{m}^{2}$

$v \quad$ Kinematic viscosity, $\mathrm{m}^{2} / \mathrm{s}$

$\rho \quad$ Density, $\mathrm{kg} / \mathrm{m}^{3}$

$\rho c_{p} \quad$ Heat capacity, $\mathrm{kg} / \mathrm{m}^{3} \mathrm{~K}$

$\theta \quad$ Dimensionless temperature

$\Psi \quad$ Stream function 


\section{Subscripts \\ nf Nanofluid \\ CNT Carbon nanotube \\ $\mathrm{f} \quad$ Base fluid}

$\begin{array}{ll}\text { Abbreviations } \\ \text { CNT } & \text { carbon nanotube } \\ \text { SWCNT } & \text { Single-wall carbon nanotube } \\ \text { MWCNT } & \text { Multi-wall carbon nanotube }\end{array}$

\section{Introduction}

Due to low thermal conductivity of heat transfer fluids used in power generation, microelectronics cooling, chemical production, refrigeration and air-conditioning, transportation, and many other applications., it is necessary to enhance effective thermal conductivity of these fluids to improve heat transfer rate. One of the techniques, to enhance effective thermal conductivity of these heat transfer fluids, is to add nanoparticles or nanotubes in the base fluids. After Choi and Eastman (1995) and Choi et al. (2001), it has been proved experimentally by many researchers (Masuda et al. 1993; Das et al. 2003; Pak and Cho 1998; Xuan and Li 2003; Eastman et al. 2001; Mintsa et al. 2009) that even with small solid volume fraction of nanoparticles (usually less than 5 $\%$ ), the thermal conductivity of heat transfer fluids can be enhanced by $10-50 \%$. These studies have been reviewed by Trisaksri and Wongwises (2007), Wang and Mujumdar (2007), Eastman et al. (2004), and Kakaç and Pramuanjaroenkij (2009), among others.

Carbon nanotubes (CNTs), due to cylindrical carbon molecules origin, are found to have special thermal properties with very high thermal conductivities. The diameter of CNTs ranges from $\sim 1$ to $\sim 100 \mathrm{~nm}$ and has lengths in micrometer. The thermal conductivity of single-wall CNT up to $6,600 \mathrm{~W} / \mathrm{mK}$ and for multi-wall CNT up to 3,000 W/m K has been reported in Hone (2004) and Antar et al. (2012). Ding et al. (2006) investigated the heat transfer behavior of CNT nanofluids flowing through a horizontal tube. They observed significant enhancement of the convective heat transfer and found that the enhancement depends on the Reynolds number and solid volume fraction of CNTs. Kamali and Binesh (2010) numerically investigated the convective heat transfer of multi-wall carbon nanotube (MWCNT)-based nanofluids in a straight tube under constant wall heat flux condition. They solved Navier Stokes equations using the finite volume technique considering CNT-based nanofluids using power law model. They found that the heat transfer coefficient is dominated by the wall region due to non-Newtonian behavior of CNT nanofluid. Meyer et al. (2013) investigated experimentally the convective heat transfer enhancement of aqueous suspensions of multi-walled CNTs flowing through a straight horizontal tube. They determined the heat transfer coefficients and friction factors as a function of Reynolds number. They found that heat transfer was enhanced when comparing the data on a Reynolds Nusselt graph and the increase in viscosity was four times the increase in the thermal conductivity. Wang et al. (2013) experimentally investigated the heat transfer and pressure drop of nanofluids containing CNTs in a horizontal circular tube. The friction factors of the dilute nanofluids were found to be in good agreement with the prediction from the Hagen-Poiseuille flow theory. They also found a considerable enhancement in the average convective heat transfer compared with the distilled water. They showed that the nanofluids at low concentration enhance the heat transfer with little extra penalty in pump power. Kumaresan et al. (2012) reported an experimental study on the convective heat transfer characteristics of a secondary refrigerant-based CNT nanofluids in a tubular heat exchanger. They found $\sim 160 \%$ enhancement in the convective heat transfer coefficient for the nanofluid containing 0.45 vol\% MWCNT and the negligible enhancement in the friction factor at higher velocity and higher temperature for the nanofluids with 0.15 vol\% MWCNT. Hong et al. (2007) reported that the thermal conductivity of the heat transfer nanofluids could be enhanced by the external magnetic field. These nanofluids contain CNTs and magneticfield-sensitive nanoparticles of $\mathrm{Fe}_{2} \mathrm{O}_{3}$. They also found that the time to reach the maximum peak value of TC is increased as the applied magnetic field is reduced. Liu and Liang (2010) developed a new kind of aqueous drag-reducing fluid with CNTs. This has both special effects of drag-reducing and heat transfer enhancement. They conducted experiments and investigated the forced convective flow and heat transfer characteristics of conventional drag-reducing fluid. They found obvious differences of the heat transfer characteristics between both fluids and concluded that the new nanofluid has strong dependences on the liquid temperature, the nanoparticle concentration and the CTAC concentration.

The objective of the present study was to analyze the flow and heat transfer of CNT nanofluids along a flat plate. A similarity solution is obtained which depends on Prandtl number, solid volume fraction of CNTs and Navier slip parameter. The dependency of the skin friction and the local Nusselt numbers on these parameters is numerically investigated. To the best of our knowledge, the results of this paper are new and they have not been published before.

\section{Theoretical models for effective thermal conductivity}

Several theoretical models, capable of predicting the effective thermal conductivity enhancement of CNT suspensions, are available in open literature. All of these models are based on Fourier's law of heat conduction. 
Maxwell (1904) proposed an explicit relation for the effective thermal conductivity in terms of the thermal conductivity ratio, $\alpha=k_{\mathrm{CNT}} / k_{\mathrm{f}}$, and the volume fraction $\phi$ :

$\frac{k_{\mathrm{nf}}}{k_{\mathrm{f}}}=1+\frac{3(\alpha-1) \phi}{(\alpha+2)+(\alpha-1) \phi}$.

Considering higher orders of volume fraction, Jeffery (1973) and Davis (1986) proposed the following theoretical models

$\frac{k_{\mathrm{nf}}}{k_{\mathrm{f}}}=1+3 \lambda \phi+\left(3 \lambda^{2}+\frac{3 \lambda^{2}}{4}+\frac{9 \lambda^{3}}{16} \frac{\alpha+2}{2 \alpha+3}+\cdots\right) \phi^{2}$

and

$\frac{k_{\mathrm{nf}}}{k_{\mathrm{f}}}=1+\frac{3(\alpha-1) \phi}{(\alpha+2)+(\alpha-1) \phi}\left\{\phi+\phi(\alpha) \phi^{2}+O\left(\phi^{3}\right)\right\}$

respectively, where $\lambda=(\alpha-1) /(\alpha+2)$. The higher order terms represent pair interactions of randomly dispersed spheres. For low-volume fractions, the above three models result nearly identical predictions of the effective thermal conductivity. Furthermore, these models do not compensate for the shape factor of the particles. Hamilton and Crosser (1962) developed a theoretical model which accounts for the shape factor of the particles

$\frac{k_{\mathrm{nf}}}{k_{\mathrm{f}}}=\frac{\alpha+(n-1)-(n-1)(1-\alpha) \phi}{\alpha+(n-1)+(1-\alpha) \phi}$

where $n$ is the shape factor of a particle given by $n=3 / \varphi^{\omega}$, where $\varphi=1$ for spheres and 0.5 for cylinders and $\omega$ ranges from 1 to 2. When $\varphi=1$, the Hamilton and Crosser (HC) model reduces to Maxwell model. Choi et al. (2001) shows that for cylindrical shape particles the HC model $(n=6)$ significantly underestimated the experimental data by showing a very minor increase of about $10 \%$ for $1.0 \mathrm{vol} \%$ nanotubes in oil in comparison to the $160 \%$ experimental enhancement in the thermal conductivity.

Xue (2005) noticed that the existing models are only valid for spherical or rotational elliptical particles with small axial ratio. Furthermore, these models do not account for the effect of the space distribution of the CNTs on thermal conductivity. Xue (2005) proposed a theoretical model based on Maxwell theory considering rotational elliptical nanotubes with very large axial ratio and compensating the effects of the space distribution on CNTs

$\frac{k_{\mathrm{nf}}}{k_{\mathrm{f}}}=\frac{1-\phi+2 \phi \frac{k_{\mathrm{CNT}}}{k_{\mathrm{CNT}}-k_{\mathrm{f}}} \ln \frac{k_{\mathrm{CNT}}+k_{\mathrm{f}}}{2 k_{\mathrm{f}}}}{1-\phi+2 \phi \frac{k_{\mathrm{f}}}{k_{\mathrm{CNT}}-k_{\mathrm{f}}} \ln \frac{k_{\mathrm{CNT}}+k_{\mathrm{f}}}{2 k_{\mathrm{f}}}}$

In this study, we have employed Xue (2005) model to determine thermal conductivity and the dimensionless heat transfer rates of nanofluids. In the next section, we will develop the mathematical model to investigate the skin friction and the dimensionless heat transfer rates of different nanofluids. In "Numerical method" we will discuss the numerical approach to solve the proposed model. Finally, we will present the physical interpretation and significance of our results.

\section{Mathematical model}

We consider the two-dimensional flow over a flat plate with heat transfer in a water/oil-based nanofluids containing single- and multi-wall CNTs. The plate surface is subjected to a uniform surface heat flux. The flow is assumed to be laminar, steady, and incompressible. The base fluids and the CNTs are assumed to be in thermal equilibrium. The slip between nanofluids and the plate surface is included in the hydrodynamic boundary condition. The viscous dissipation and radiation effects are neglected in the energy equation. The ambient temperature is assumed to be constant. Using order of magnitude analysis, the standard boundary layer equations for this problem can be written as follows:

$\frac{\partial u}{\partial x}+\frac{\partial v}{\partial y}=0$

$u \frac{\partial u}{\partial x}+v \frac{\partial u}{\partial y}=v_{\mathrm{nf}} \frac{\partial^{2} u}{\partial y^{2}}$

$u \frac{\partial T}{\partial x}+v \frac{\partial T}{\partial y}=\alpha_{\mathrm{nf}} \frac{\partial^{2} T}{\partial y^{2}}$

where $u$ and $v$ are the velocity components along the $x$ - and $y$-axes, $T$ is the temperature, $v_{\mathrm{nf}}$ and $\alpha_{\mathrm{nf}}$ are the effective kinematic viscosity and thermal diffusivity of nanofluids, respectively. The effective properties of nanofluids may be expressed in terms of the properties of base fluid and carbon nanotubes, and the solid volume fraction of CNTs in the base fluids as follows:

$$
\left.\begin{array}{c}
\rho_{\mathrm{nf}}=(1-\phi) \rho_{\mathrm{f}}+\phi \rho_{\mathrm{CNT}}, \quad \mu_{\mathrm{nf}}=\frac{\mu_{\mathrm{f}}}{(1-\phi)^{2.5}} \\
\left(\rho c_{p}\right)_{\mathrm{nf}}=(1-\phi)\left(\rho c_{p}\right)_{\mathrm{f}}+\phi\left(\rho c_{p}\right)_{\mathrm{CNT}} \\
v_{\mathrm{nf}}=\frac{\mu_{\mathrm{nf}}}{\rho_{\mathrm{nf}}}, \quad \alpha_{\mathrm{nf}}=\frac{k_{\mathrm{nf}}}{\left(\rho c_{p}\right)_{\mathrm{nf}}}
\end{array}\right\}
$$

where $k_{\mathrm{nf}}$ is the thermal conductivity of the nanofluid (see Eq.5), $\left(\rho c_{p}\right)_{\mathrm{nf}}$ is the heat capacity of nanofluid and $\phi$ is the solid volume fraction of nanofluid. The hydrodynamic and thermal boundary conditions for the problem can be written as

$$
\left.v=0, u=\gamma \partial u / \partial y,-k \partial T / \partial y=q_{\mathrm{w}}, \text { at } y=0\right\}
$$

where $\gamma$ is the slip parameter and $U_{\infty}$ is the free stream velocity. We look for a similarity solution of Eqs. (6), (7), (8), (9) and (10) of the following form 


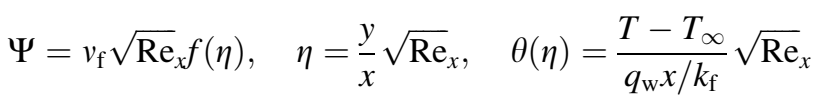

where $\eta$ is the similarity variable and $\operatorname{Re}_{x}=U_{\infty} x / v_{f}$ is the local Reynolds number based on the free stream velocity and the kinematic viscosity of the base fluid. The stream function $\Psi$ is defined as $u=\partial \Psi / \partial y$ and $v=-\partial \Psi / \partial x$. Employing the similarity variables (11), Eqs. (6), (7) and (8) reduce to the following nonlinear system of ordinary differential equations:

$\frac{1}{(1-\phi)^{2.5}\left(1-\phi+\phi \rho_{\mathrm{CNT}} / \rho_{\mathrm{f}}\right)} f^{\prime \prime \prime}+\frac{1}{2} f f^{\prime \prime}=0$

$\frac{1}{\operatorname{Pr}} \frac{k_{\mathrm{nf}} / k_{\mathrm{f}}}{\left\{1-\phi+\phi\left(\rho c_{p}\right)_{\mathrm{CNT}} /\left(\rho c_{p}\right)_{\mathrm{f}}\right\}} \theta^{\prime \prime}+\frac{1}{2}\left(f \theta^{\prime}-f^{\prime} \theta\right)=0$

subjected to the boundary conditions (10) which become

$$
\left.\begin{array}{c}
f(0)=0, \quad f^{\prime}(0)=\frac{\beta}{(1-\phi)^{2.5}} f^{\prime \prime}(0), \quad \theta^{\prime}(0)=-\frac{k_{\mathrm{f}}}{k_{\mathrm{nf}}} \\
f^{\prime} \rightarrow 1, \quad \theta \rightarrow 0, \text { as } \quad \eta \rightarrow \infty
\end{array}\right\}
$$

Here, primes denote differentiation with respect to $\eta, \operatorname{Pr}=\left(\mu c_{p}\right)_{\mathrm{f}} / k_{\mathrm{f}}$ is the Prandtl number of the base fluid and $\beta=U_{\infty} \gamma / v_{\mathrm{f}}$ is the dimensionless slip parameter.

The physical quantities of interest are the skin friction coefficient $C_{\mathrm{f}}$ and the local Nusselt number $\mathrm{Nu}_{x}$, which are defined as

$C_{\mathrm{f}}=\frac{\tau_{\mathrm{w}}}{\rho_{\mathrm{f}} U_{\infty}^{2}}, \quad \mathrm{Nu}_{x}=\frac{x q_{\mathrm{w}}}{k_{\mathrm{f}}\left(T_{\mathrm{w}}-T_{\infty}\right)}$

where the surface shear stress $\tau_{\mathrm{w}}$ and the surface heat flux $q_{\mathrm{w}}$ are given by

$\tau_{\mathrm{w}}=\mu_{\mathrm{nf}}\left(\frac{\partial u}{\partial y}\right)_{y=0}, \quad q_{\mathrm{w}}=-k_{\mathrm{nf}}\left(\frac{\partial T}{\partial y}\right)_{y=0}$

with $\mu_{\mathrm{nf}}$ and $k_{\mathrm{nf}}$ being the dynamic viscosity and the thermal conductivity of the nanofluids, respectively. Using the similarity variables (11), we obtain

$$
\operatorname{Re}_{x}^{1 / 2} C_{\mathrm{f}}=\frac{1}{(1-\phi)^{2.5}} f^{\prime \prime}(0), \quad \operatorname{Re}_{x}^{-1 / 2} \mathrm{Nu}_{x}=\frac{k_{\mathrm{nf}}}{k_{\mathrm{f}}} \frac{1}{\theta(0)}
$$

\section{Numerical method}

An efficient finite difference method along with shooting technique has been employed to solve the coupled nonlinear ordinary differential Eqs. (12) and (13) subject to the boundary conditions (14) for different values of governing parameters including Prandtl number Pr, velocity slip parameter $\beta$ and CNT volume fraction $\phi$. The boundary value problem is first transformed into an initial value problem (IVP). Then, the IVP is solved by a systematic guessing for $f^{\prime \prime}(0)$ and $\theta^{\prime}(0)$ until the boundary conditions have been at $\infty$, asymptotically decay to zero. The step size $\Delta \eta=0.001$ is used to obtain the numerical solution with $\eta_{\max }=7$ to ensure the convergence in each case, where $\eta_{\max }$ is the finite value of the similarity variable $\eta$ for the far field boundary conditions.

\section{Results and discussion}

The flow and heat transfer of single- and multi-wall CNTs in three different base fluids have been investigated. The governing partial differential equations and the corresponding boundary conditions are converted into a set of nonlinear ordinary differential equations and these equations are solved numerically. Thermophysical properties of base fluids and CNTs are presented in Table 1. The variation in the thermophysical properties of different nanofluids with solid volume fraction of single- and multi-wall CNTs is shown in Table 2. The percentage increase in the thermal conductivities of different nanofluids can be predicated from Table 2. For example, the enhancement in thermal conductivity of $0.04 \%$ SWCNT or MWCNT in oil is 83 and $77 \%$, respectively. It is clear that the density and thermal conductivity increase whereas heat capacity decreases with the solid volume fraction for each CNT. It is observed that water-based CNTs have higher densities and thermal conductivities than kerosene- or engine oil-based CNTs. This is due to higher density and thermal conductivity of water as shown in Table 1.

In the absence of slip, the reduced Nusselt number for pure fluids is given by Kays and Crawford (2005) which is expressed as

$\mathrm{Re}_{x}^{-1 / 2} \mathrm{Nu}_{x}=0.453 \operatorname{Pr}_{\mathrm{f}}^{1 / 3}$

The present numerical values of Nusselt numbers for pure fluids are compared with Eq. (18) in Table 3 and are found in an excellent agreement. Table 4 illustrates the variation of skin friction and Nusselt numbers with solid volume fraction and slip parameter for different nanofluids. It is observed that due to higher density of single-wall CNTs, the skin friction is higher than multi-wall CNTs with all base fluids. Furthermore, the skin friction increases with solid volume fraction due to increase in density of both CNTs and decreases with slip parameter due to increase in the velocity at the surface in all cases. Unlike skin friction, a large enhancement in the dimensionless heat transfer rates with the solid volume fraction and slip parameter could be observed in all nanofluids.

The effects of the governing parameters on the dimensionless velocity, temperature, skin friction, and Nusselt 
Table 1 Thermophysical properties of different base fluids and CNTs (Hone 2004; Antar et al. 2012; Oztop and Abu-Nada 2008; EbrahimniaBajestan and Niazmand 2011; Bejan 2004)

\begin{tabular}{|c|c|c|c|c|c|}
\hline \multirow[t]{2}{*}{ Physical properties } & \multicolumn{3}{|c|}{ Base fluids } & \multicolumn{2}{|c|}{ Nanoparticles } \\
\hline & Water & Kerosene & Engine oil & SWCNT & MWCNT \\
\hline$\rho\left(\mathrm{kg} / \mathrm{m}^{3}\right)$ & 997 & 783 & 884 & 2,600 & 1,600 \\
\hline$c_{p}(\mathrm{~J} / \mathrm{kg} \mathrm{K})$ & 4,179 & 2,090 & 1,910 & 425 & 796 \\
\hline$k(\mathrm{~W} / \mathrm{m} \mathrm{K})$ & 0.613 & 0.145 & 0.144 & 6,600 & 3,000 \\
\hline
\end{tabular}

Table 2 Variation of thermophysical properties of nanofluids with solid volume fraction of CNTs

\begin{tabular}{llrlllllll}
\hline SWCNT & $\phi$ & $\rho$ & $\rho c_{p}\left(\times 10^{6}\right)$ & $k$ & MWCNT & \multicolumn{1}{l}{$\phi$} & $\rho$ & $\rho c_{p}\left(\times 10^{6}\right)$ & $k$ \\
\hline Water & 0 & 997 & 4.167 & 0.613 & Water & 0 & 997 & 4.167 & 0.613 \\
& 0.04 & 1,061 & 4.044 & 1.051 & & 0.04 & 1,021 & 4.051 & 1.011 \\
& 0.08 & 1,125 & 3.921 & 1.528 & & 0.08 & 1,045 & 3.935 & 1.444 \\
& 0.12 & 1,189 & 3.799 & 2.048 & & 0.12 & 1,069 & 3.819 & 1.916 \\
& 0.16 & 1,253 & 3.676 & 2.618 & & 0.16 & 1,093 & 3.703 & 2.434 \\
& 0.2 & 1,317 & 3.554 & 3.245 & & 0.2 & 1,117 & 3.588 & 3.002 \\
Kerosene & 0 & 783 & 1.636 & 0.150 & Kerosene & 0 & 783 & 1.636 & 0.150 \\
& 0.04 & 855 & 1.615 & 0.274 & & 0.04 & 815 & 1.621 & 0.265 \\
& 0.08 & 928 & 1.593 & 0.410 & & 0.08 & 848 & 1.607 & 0.390 \\
& 0.12 & 1,001 & 1.572 & 0.559 & & 0.12 & 881 & 1.592 & 0.526 \\
& 0.16 & 1,073 & 1.551 & 0.721 & & 0.16 & 913 & 1.578 & 0.676 \\
& 0.2 & 1,146 & 1.530 & 0.899 & & 0.2 & 946 & 1.563 & 0.840 \\
Engine oil & 0 & 884 & 1.688 & 0.144 & Engine oil & 0 & 884 & 1.688 & 0.144 \\
& 0.04 & 952 & 1.665 & 0.264 & & 0.04 & 912 & 1.671 & 0.255 \\
& 0.08 & 1,021 & 1.641 & 0.395 & & 0.08 & 941 & 1.655 & 0.375 \\
& 0.12 & 1,089 & 1.618 & 0.538 & & 0.12 & 969 & 1.638 & 0.507 \\
& 0.16 & 1,158 & 1.595 & 0.694 & & 0.16 & 998 & 1.622 & 0.651 \\
& 0.2 & 1,227 & 1.571 & 0.866 & & 0.2 & 1,027 & 1.605 & 0.809 \\
\hline
\end{tabular}

Table 3 Comparison of Nusselt numbers for pure fluids in the absence of slip velocity

\begin{tabular}{llll}
\hline & Eq. (18) & Present results & $\%$ Difference \\
\hline Water $(\operatorname{Pr}=6.2)$ & 0.8303 & 0.8503 & 2.4 \\
Kerosene $(\operatorname{Pr}=21)$ & 1.2470 & 1.2785 & 2.5 \\
Engine oil $(\operatorname{Pr}=6450)$ & 8.4137 & 8.6311 & 2.6 \\
\hline
\end{tabular}

numbers are investigated and presented in Figs. 1, 2, 3, 4 and 5. Figure 1 illustrates the effects of solid volume fraction of both CNTs and velocity slip parameter on the dimensionless velocity for three different base fluids. In the absence of slip velocity, the dimensionless velocity at the surface is found to be zero and it increases with velocity slip in all three cases. Within the hydrodynamic boundary layer, the velocity increases with the solid volume fraction of each CNT and approaches to the free stream velocity with the same boundary layer thickness for all the three fluids. The dimensionless surface temperature decreases with an increase in the solid volume fraction of both CNTs and the velocity slip parameter, as shown in Fig. 2. This is due to increase in thermal conductivity of CNTs with the solid volume fraction and increase in velocity with the slip parameter. As expected, the thermal boundary layer thickness decreases with an increase in Prandtl numbers. This is obvious from Fig. 2a-c. The thermal boundary layer thickness of kerosene $(\operatorname{Pr}=21)$ is in between water $(\operatorname{Pr}=6.2)$ and engine oil $(\operatorname{Pr}=6450)$.

The variation of skin friction with solid volume fraction of both CNTs and Navier slip parameter is shown in Fig. 3a-c for three different base fluids. Due to increase in density of CNTs with solid volume fraction, the skin friction increases with solid volume fraction and decreases with Navier slip in all three cases. In the absence of Navier slip, the skin friction is found to be highest for SWCNTs and it decreases with an increase in Navier slip in each case. It is important to note that, in the absence of slip, the skin friction for pure fluids is found to be 0.332 which could be found in any fluid mechanics or heat transfer text book. 
Table 4 Variation of skin friction and Nusselt number with solid volume fraction for different values of velocity slip

\begin{tabular}{|c|c|c|c|c|c|c|c|}
\hline & \multirow[t]{2}{*}{$\phi$} & \multicolumn{3}{|l|}{$\operatorname{Re}_{x}^{1 / 2} C_{\mathrm{f}}$} & \multicolumn{3}{|l|}{$\operatorname{Re}_{x}^{-1 / 2} \mathrm{Nu}_{x}$} \\
\hline & & $\beta=0$ & $\beta=1$ & $\beta=2$ & $\beta=0$ & $\beta=1$ & $\beta=2$ \\
\hline \multicolumn{8}{|l|}{ Water-based } \\
\hline \multirow[t]{3}{*}{ SWCNT } & 0.01 & 0.33894 & 0.29879 & 0.24258 & 1.10553 & 1.76247 & 2.08260 \\
\hline & 0.1 & 0.40811 & 0.34519 & 0.26885 & 4.80627 & 7.26946 & 8.35604 \\
\hline & 0.2 & 0.50452 & 0.40205 & 0.29806 & 12.30317 & 18.37478 & 20.68745 \\
\hline \multirow[t]{3}{*}{ MWCNT } & 0.01 & 0.33727 & 0.29760 & 0.24187 & 1.07905 & 1.72277 & 2.03718 \\
\hline & 0.1 & 0.39008 & 0.33358 & 0.26250 & 4.27718 & 6.51476 & 7.52952 \\
\hline & 0.2 & 0.46466 & 0.37958 & 0.28688 & 10.56783 & 15.95946 & 18.13612 \\
\hline \multicolumn{8}{|c|}{ Kerosene-based } \\
\hline \multirow[t]{3}{*}{ SWCNT } & 0.01 & 0.34013 & 0.29963 & 0.24307 & 1.73471 & 3.20033 & 3.87797 \\
\hline & 0.1 & 0.42046 & 0.35296 & 0.27303 & 8.79741 & 15.23033 & 17.91237 \\
\hline & 0.2 & 0.53105 & 0.41624 & 0.304910 & 23.99051 & 41.11492 & 47.21425 \\
\hline \multirow[t]{3}{*}{ MWCNT } & 0.01 & 0.33800 & 0.29812 & 0.24218 & 1.69363 & 3.12961 & 3.79541 \\
\hline & 0.1 & 0.39807 & 0.33876 & 0.26535 & 7.89921 & 13.78040 & 16.31197 \\
\hline & 0.2 & 0.48251 & 0.38981 & 0.29203 & 20.90941 & 36.30030 & 42.14878 \\
\hline \multicolumn{8}{|c|}{ Engine oil-based } \\
\hline \multirow[t]{3}{*}{ SWCNT } & 0.01 & 0.33950 & 0.29918 & 0.24281 & 11.71677 & 51.59836 & 65.48344 \\
\hline & 0.1 & 0.41393 & 0.34888 & 0.27084 & 59.37852 & 241.76530 & 299.86564 \\
\hline & 0.2 & 0.51710 & 0.40885 & 0.30137 & 161.54843 & 653.29337 & 789.77258 \\
\hline \multirow[t]{3}{*}{ MWCNT } & 0.01 & 0.33761 & 0.29785 & 0.24202 & 11.44183 & 50.48738 & 64.11329 \\
\hline & 0.1 & 0.39384 & 0.33602 & 0.26385 & 53.39949 & 219.32584 & 273.59827 \\
\hline & 0.2 & 0.47310 & 0.38445 & 0.28934 & 141.06211 & 578.27032 & 706.41293 \\
\hline
\end{tabular}
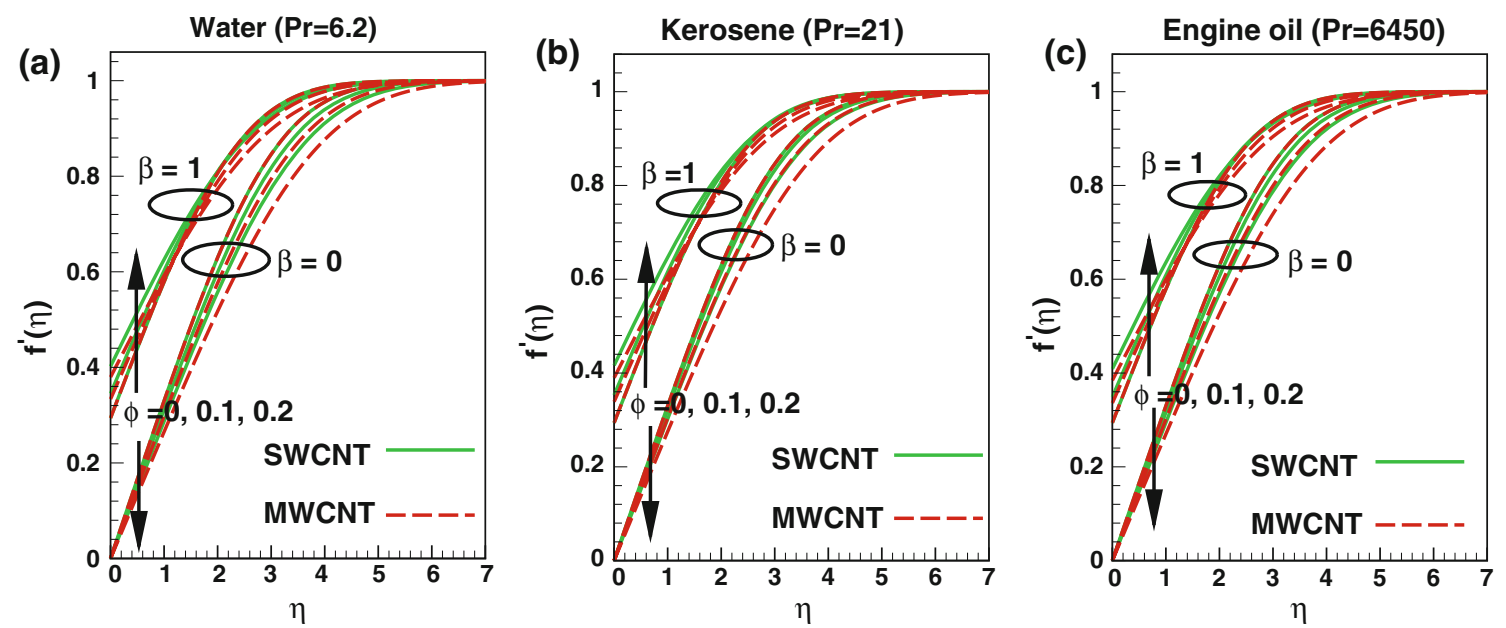

Fig. 1 Effects of nanoparticle volume fraction and slip parameters on dimensionless velocity for CNTs with different base fluids

Figure 4 shows the variation of Nusselt number with solid volume fraction of both CNTs and Navier slip for all three base fluids. Due to increase in thermal conductivities of each CNT with solid volume fraction, Nusselt numbers also increase with solid volume fraction. In the absence of Navier slip, Nusselt numbers are lower and they increase with an increase in slip in each case. This is due to an increase in velocity at the surface. All nanofluids show remarkable increase in heat transfer rate due to higher values of Prandtl numbers and thermal conductivities.

A comparison of different theoretical models of thermal conductivity is presented in Fig. 5 for SWCNTs with different base fluids. The measured enhancement in heat transfer rate using the Xue (2005) thermal conductivity model for $0.05 \%$ vol SWCNT in water is $186 \%$, whereas the enhancement predicted by $\mathrm{HC}$ model is $54 \%$ and the 

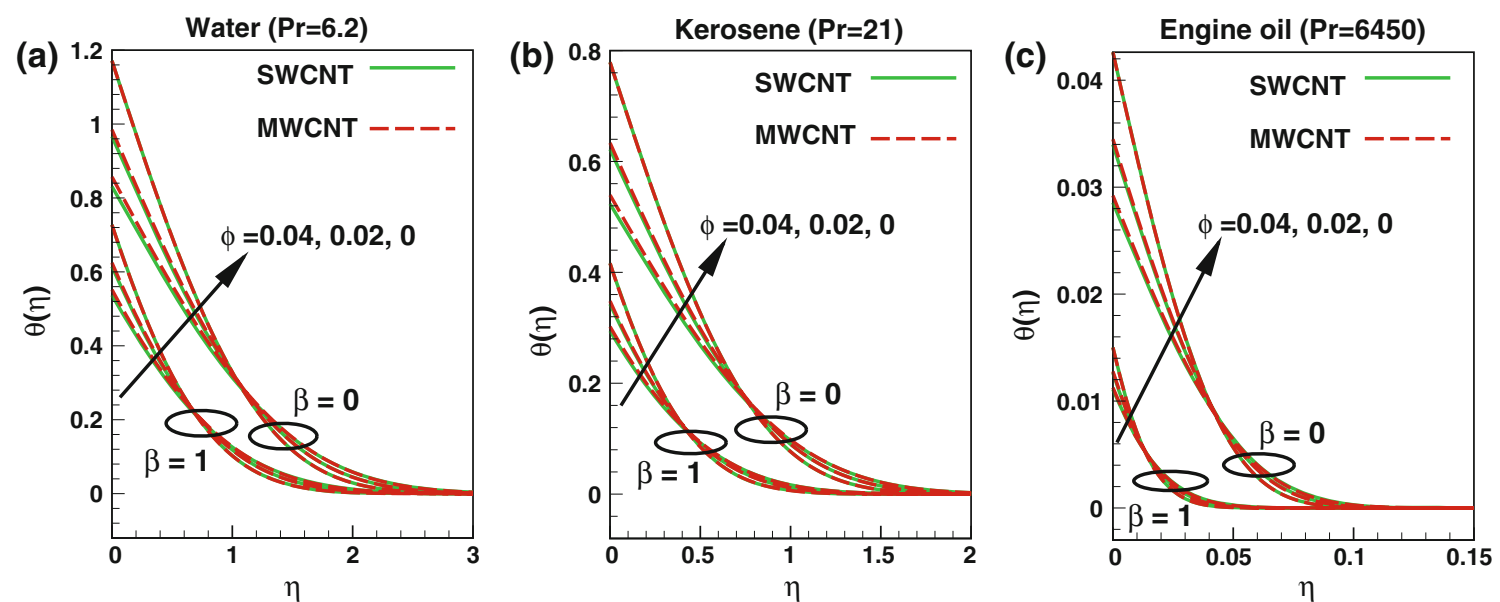

Fig. 2 Effects of nanoparticle volume fraction and slip parameters on dimensionless temperature for CNTs with different base fluids
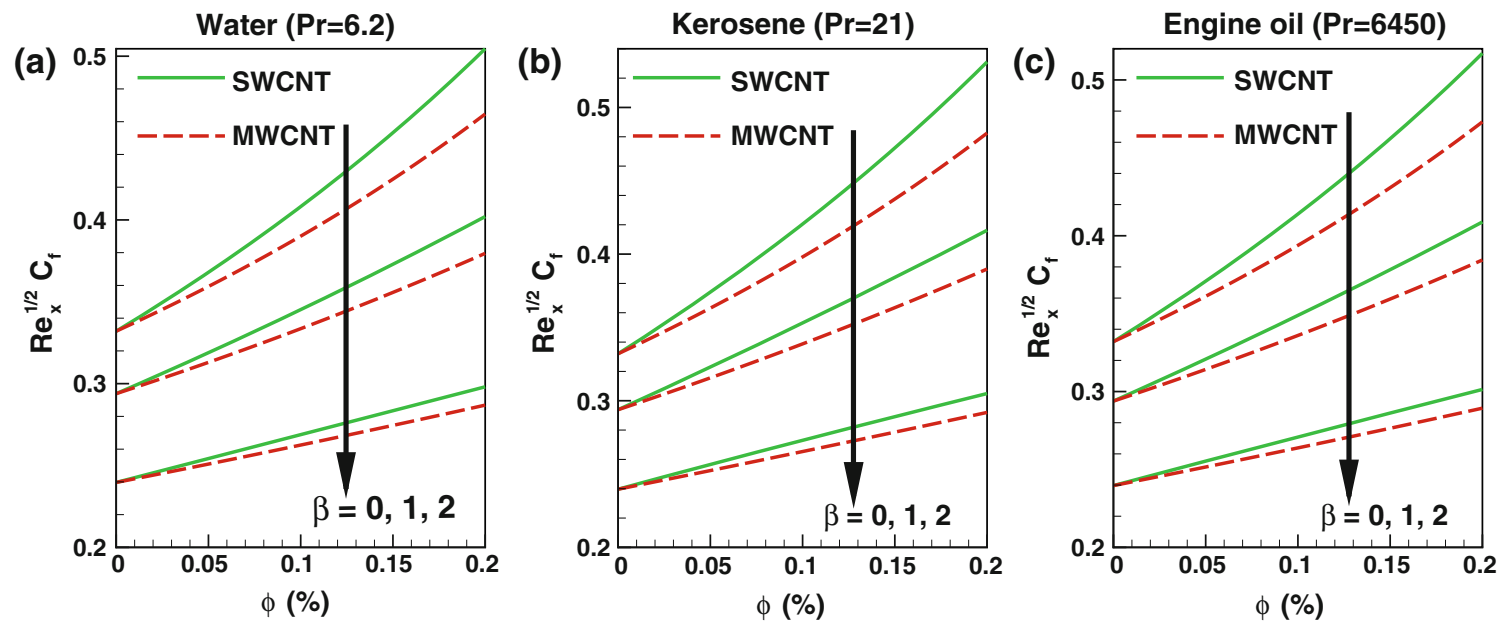

Fig. 3 Variation of skin friction coefficient with CNT volume fraction $\phi$ and Navier slip parameter $\beta$ for different base fluids
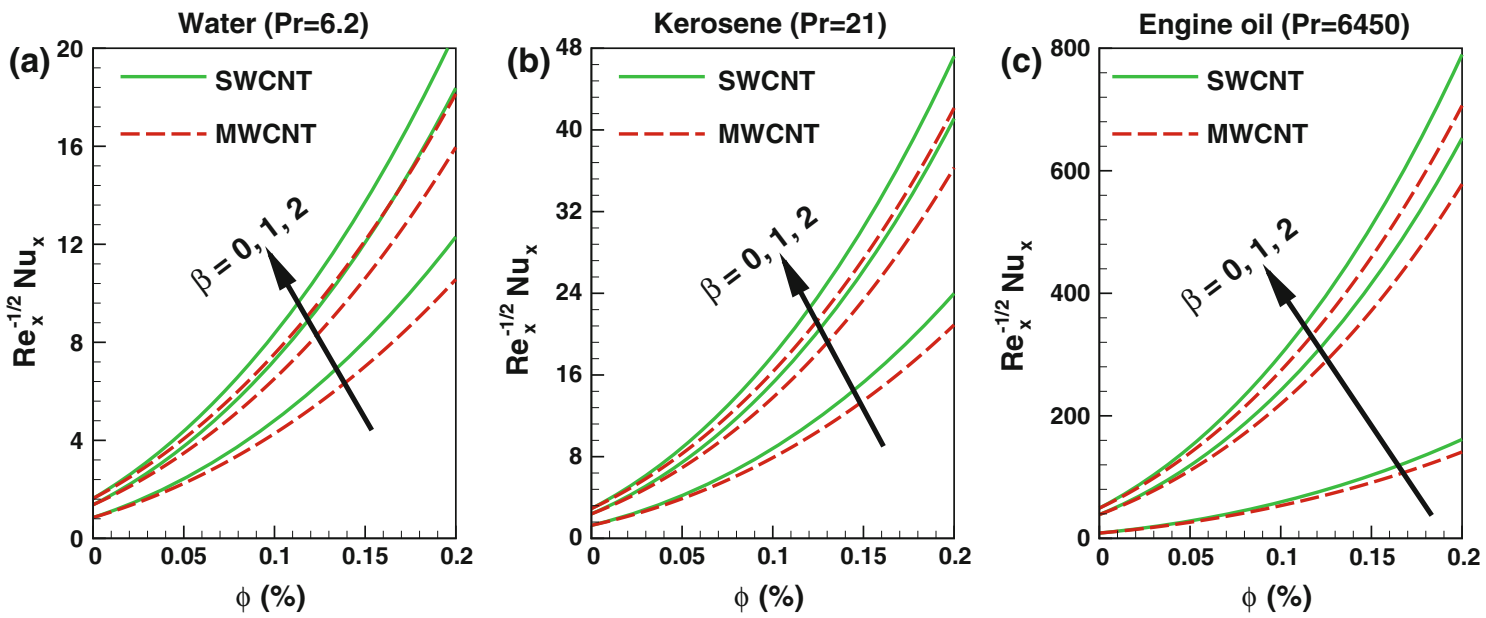

Fig. 4 Variation of Nusselt number with CNT volume fraction $\phi$ and Navier slip parameter $\beta$ for different base fluids 

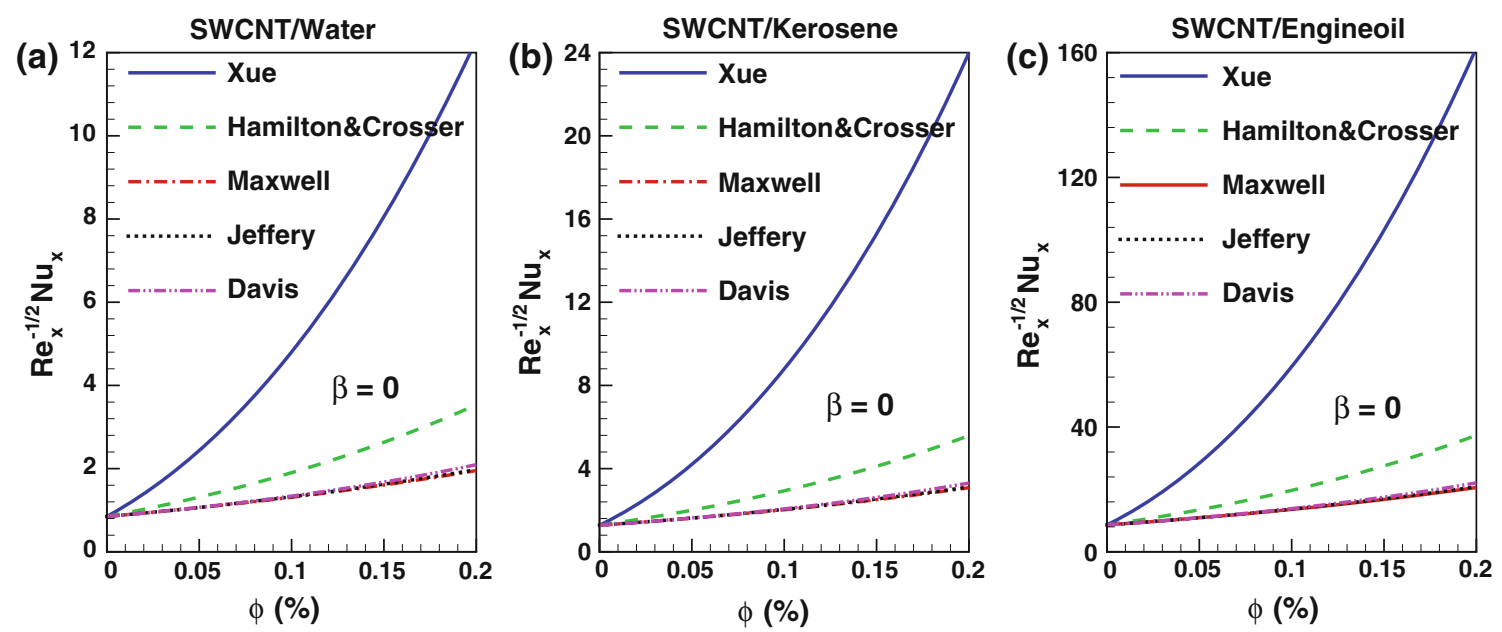

Fig. 5 Comparison among the theoretical models for single-wall CNT with different base fluids. In the calculation, $n=6$ for the HC model; $\phi$ $(\alpha)=0.5$ for Davis model

enhancement predicted by the other three models is nearly $25 \%$ (see Fig. 5a). A similar comparison for the keroseneor engine oil-based SWCNT can be made from Fig. 5b and c, respectively.

\section{Conclusions}

The present study investigates the flow and heat transfer of nanofluids along flat plate with Navier slip velocity boundary condition. It is concluded that

1. The effect of slip parameter is to reduce friction and increase heat transfer rate.

2. The skin friction and heat transfer rates increase with CNT volume fraction.

3. Engine oil-based CNTs have higher heat transfer rates than water and kerosene-based CNTs.

4. Kerosene-based CNTs have higher skin friction than engine oil and water-based CNTs.

Open Access This article is distributed under the terms of the Creative Commons Attribution License which permits any use, distribution, and reproduction in any medium, provided the original author(s) and the source are credited.

\section{References}

Antar Z, Noel H, Feller JF, Glouannec P, Elleuch K (2012) Thermophysical and radiative properties of conductive biopolymer composite. Mater Sci Forum 714:115-122

Bejan A (2004) Convection heat transfer, 3rd edn. John Wiley, New York

Choi S, Eastman J (1995) Enhancing thermal conductivity of fluids with nanoparticles. In: The proceedings of the 1995 ASME international mechanical engineering congress and exposition, San Francisco, pp 99-105

Choi SUS, Zhang ZG, Yu W, Lockwood FE, Grulke EA (2001) Anomalous thermal conductivity enhancement in nanotube suspensions. Appl Phys Lett 79(14):2252-2254

Das SK, Putra N, Thiesen P, Roetzel W (2003) Temperature dependence of thermal conductivity enhancement for nanofluids. J Heat Transf 125(4):567-574

Davis R (1986) The effective thermal conductivity of a composite material with spherical inclusions. Inter $\mathrm{J}$ Thermophys 7:609-620

Ding Y, Alias H, Wen D, Williams RA (2006) Heat transfer of aqueous suspensions of carbon nanotubes (CNT nanofluids). Int J Heat Mass Transf 49(1-2):240-250

Eastman JA, Choi SUS, Li S, Yu W, Thompson LJ (2001) Anomalously increased effective thermal conductivities of ethylene glycol-based nanofluids containing copper nanoparticles. Appl Phys Lett 78(6):718-720

Eastman J, Phillpot S, Choi S, Keblinski P (2004) Thermal transport in nanofluids. Annu Rev Mater Res 34:219-246

Ebrahimnia-Bajestan E, Niazmand H (2011) Convective heat transfer of nanofluids flows through an isothermally heated curved pipe. Iran J Chem Eng 8(2):81-97

Hamilton RL, Crosser OK (1962) Thermal conductivity of heterogeneous two-component systems. Ind Eng Chem Fund 1(3):187-191

Hone J (2004) Carbon nanotubes: thermal properties. Dekker Encycl Nanosci Nanotechnol 603-610

Hong H, Wright B, Wensel J, Jin S, Ye XR, Roy W (2007) Enhanced thermal conductivity by the magnetic field in heat transfer nanofluids containing carbon nanotube. Synth Metals 157(10-12):437-440

Jeffrey DJ (1973) Conduction through a random suspension of spheres. Proc Roy Soc Lond Ser A Math Phys Sci 335:355-367

Kakaç S, Pramuanjaroenkij A (2009) Review of convective heat transfer enhancement with nanofluids. Int J Heat Mass Transf 52(13-14):3187-3196

Kamali R, Binesh A (2010) Numerical investigation of heat transfer enhancement using carbon nanotube-based non-Newtonian nanofluids. Int Commun Heat Mass Transf 37(8):1153-1157

Kays W, Crawford M (1980) Convective heat and mass transfer. McGraw Hill 
Kumaresan V, Velraj R, Das SK (2012) Convective heat transfer characteristics of secondary refrigerant based CNT nanofluids in a tubular heat exchanger. Int J Refrig 35(8):2287-2296

Liu Z-H, Liang (2010) Forced convective flow and heat transfer characteristics of aqueous drag-reducing fluid with carbon nanotubes added. Inter J Therm Sci 49(12):2331-2338

Masuda H, Ebata A, Teramea K, Hishinuma N (1993) Alteration of thermal conductivity and viscosity of liquid by dispersing ultrafine particles. Netsu Bussei 4(4):227-233

Maxwell JC (1904) Electricity and magnetism, 3rd edn. Clarendon, Oxford

Meyer J, McKrell T, Grote K (2013) The influence of multi-walled carbon nanotubes on single-phase heat transfer and pressure drop characteristics in the transitional flow regime of smooth tubes. Int J Heat Mass Transf 58(1-2):597-609

Mintsa HA, Roy G, Nguyen CT, Doucet D (2009) New temperature dependent thermal conductivity data for water-based nanofluids. Int J Therm Sci 48(2):363-371
Oztop H, Abu-Nada E (2008) Numerical study of natural convection in partially heated rectangular enclosures filled with nanofluids. Int J Heat Fluid Flow 29(5):1326-1336

Pak BC, Cho YI (1998) Hydrodynamic and heat transfer study of dispersed fluids with submicron metallic oxide particles. Exp Heat Transf 11(2):151-170

Trisaksri V, Wongwises S (2007) Critical review of heat transfer characteristics of nanofluids. Renew Sustain Energy Rev 11(3):512-523

Wang X-Q, Mujumdar AS (2007) Heat transfer characteristics of nanofluids: a review. Inter J Therm Sci 46(1):1-19

Wang J, Zhu J, Zhang X, Chen Y (2013) Heat transfer and pressure drop of nanofluids containing carbon nanotubes in laminar flows. Exp Therm Fluid Sci 44:716-721

Xuan Y, Li Q (2003) Investigation on convective heat transfer and flow features of nanofluids. J Heat Transf 125(1):151-155

Xue Q (2005) Model for thermal conductivity of carbon nanotubebased composites. Phys B Condens Matter 368:302-307 